\title{
"Humaniza Laranjal": implantando uma política municipal de humanização
}

Stella Bianca Gonçalves Brasil

Secretaria Municipal de Saúde de Cesário Lange

Endereço: Rua Francisco Ribeiro da Silva, 225, CEP

18285-ooo, Cesário Lange, SP, Brasil.

E-mail: saude@cesariolange.sp.gov.br

Wilza Carla Spiri, Carmen Maria Casquel Monti Juliani Departamento de Enfermagem da Faculdade de Medicina de Botucatu - UNESP

Endereço: Campus Universitário da UNESP, Distrito de Rubião Junior, s/n, anexo H, $1^{\circ}$ andar, CEP 18618-970, Botucatu, SP, Brasil.

E-mail: wilza@fmb.unesp.br, cjuliani@fmb.unesp.br

Laranjal Paulista propôs uma política de humanização construída a partir de mudanças na estrutura, na forma de trabalhar e também das pessoas. 0 processo de construção permitiu elaborar conjuntamente os programas coletivos de humanização da atenção básica. Foi potencializado o amadurecimento para lidar com aspectos técnicos, políticos, humanos e éticos. Houve crescimento da capacidade de ouvir e expor críticas, de aceitar derrotas e estabelecer negociações e consensos, envolvimento e compromisso das Equipes. Foi criado o espaço de Educação Permanente, possibilitando a troca de informação. A construção coletiva pode parecer difícil no início, pois é preciso vencer resistências continuamente, mas certamente permite alcançar resultados significativos. 